\title{
Optimal Standards of Negligence When One Party is Uninformed of the Standards
}

\author{
Lando, Henrik
}

Document Version

Final published version

Publication date:

2008

License

CC BY-NC-ND

Citation for published version (APA):

Lando, H. (2008). Optimal Standards of Negligence When One Party is Uninformed of the Standards. SSRN:

Social Science Research Network.

Link to publication in CBS Research Portal

\footnotetext{
General rights

Copyright and moral rights for the publications made accessible in the public portal are retained by the authors and/or other copyright owners and it is a condition of accessing publications that users recognise and abide by the legal requirements associated with these rights.

\section{Take down policy}

If you believe that this document breaches copyright please contact us (research.lib@cbs.dk) providing details, and we will remove access to the work immediately and investigate your claim.
} 


\title{
Optimal standards of negligence when one party is uninformed of the standards ${ }^{1}$
}

\author{
Henrik Lando ${ }^{2}$ \\ Copenhagen Business School and LEFIC
}

\begin{abstract}
When a court sets standards of due care in a tort or contract case with a view to how the standards will affect future behavior of parties similar to the litigants, it should sometimes realize that only one of the two future parties is likely to become informed of the standards. The standards can then only have a direct effect on the behavior of the informed party, and it may be thought that the court should hold the informed party strictly liable, which maximizes this effect. However, this ignores that the informed party may, although strictly liable, lower her level of care in order to induce the uninformed party to take greater care. In this situation, the negligence rule may do better than strict liability, since the discontinuity of the negligence rule can prevent the informed party from strategically lowering her level of care. Under the negligence rule, optimal standards are sensitive to whether the informed party acts first and to whether she is the injurer or the victim. For both the informed and the uninformed, there are circumstances in which the standard should be higher than first best and other circumstances where it should be lower. However, in the prevalent case where the informed party is the injurer and acts first, and the uninformed understands the risk, the court should under certain conditions set the standard for the informed party set at the first best level. The uninformed should then infer that the informed party has an incentive to take due care, and so take proper precautions himself. Moreover, the court should generally apply a lenient standard of due care to the uninformed
\end{abstract}

${ }^{1}$ I wish to thank participants at the ALEA conference at Berkeley, 2006, participants at the Amsterdam Center for Law and Economics seminar, 2006, in particular Giuseppe Dari-Mattiacci, and participants at the Berkeley law and economics seminar, 2008, in particular Bob Cooter, Daniel Rubinfeld and Eric Talley. Most of all, I wish to thank my colleague, Thomas Rønde for very helpful comments. I bear responsibility for errors that may remain.

${ }^{2}$ Henrik Lando, Professor of Law and Economics, Copenhagen Business School and LEFIC,

Kilevej 14a, 3d., 2000 Frederiksberg, Denmark. Phone: +45 38152531. Fax: +45 38152540. e-mail: hl.ino@cbs.dk 
victim, as this maximizes the incentive for the informed party to take due care without diminishing the incentive of the uninformed party.

JEL: K10, K13, K14

Key words: negligence standards, one-sided legal ignorance

\section{Introduction}

When a court sets negligence standards in a tort or contract ${ }^{3}$ case and considers how alternative standards will affect the behavior of similarly situated parties in the future, it should not always assume that both future parties will become informed of the standards expressed by its verdict. In some situations, the court should realize that the standards will only become known by - and hence only affect the behavior of - one of the parties, usually the party that has specialized in the given activity. This raises the question as to whether this should cause the court to adjust its standards, e.g. by requiring more care from the informed party than it would if both parties could be relied upon to become informed of standards.

To illustrate, consider a case in which a group of employees underwent a teambuilding (survival) course organized by a professional firm ${ }^{4}$ and were told to undertake dangerous activities during which one of them was injured. Organizers of such activities are more likely to become aware of legal standards than future participants, since the organizers specialize in this activity, and the court should therefore expect to have a greater influence on the behavior of organizers than on the behavior of future participants. Applied to this case, the question becomes whether the organizer should be required to take precautions that she would not be required to undertake if the participant could be expected to be informed of standards of due care.

The issue of optimal standards under one-sided legal ignorance is analyzed within a model where the court chooses a standard of due care for the injurer and a standard of (comparative) negligence for the victim, and where these standards determine the pay-offs of the subsequent liability game played between the informed party (henceforth IN or she) and the uninformed (henceforth $U$ or he). The pay-off structure is known to IN but not to U, who may, however, attempt to infer the payoffs from IN's act. Thus, U holds an ex-ante belief concerning the standards set by the court, and when IN acts first, U updates his belief, taking into account IN's act of care. $U$ then chooses his level of precaution based on the updated belief, whereas IN

${ }^{3}$ In a contract setting, the court determines the standard of performance for the seller and the standards of mitigation by the buyer. For simplicity, the vocabulary of tort law will be used in this article.

${ }^{4}$ Court case U.1997.23V 
chooses her level of care taking into account how $U$ will respond. An equilibrium in the overall game arises when the standard chosen by the court minimizes the total social costs of the resulting equilibrium in the game between IN and U.

Concerning the scope of the analysis, the analysis bears relevance not only to tort losses but also to losses arising as a consequence of a defective good or service within contract. For services (such as e.g. advice given by lawyers, accountants, and banks), the negligence rule tends to apply, but for product liability the rule in many jurisdictions is strict liability for defective products, mainly due to the nonverifiability of the producer's level of care. This calls into question the relevance of the present analysis for product liability, as non-verifiability provides a strong argument for strict liability in the context of product liability, which may trump other considerations. However, for there to be liability, the product must not live up to the reasonable expectations of the buyer, and this requires the court to decide on a standard of reasonableness. This standard actually shares essential characteristics of the negligence rule: If the standard is met by the producer, she will avoid liability, whereas if not, the loss will be shared if the buyer has acted negligently. In this interpretation, the present analysis is relevant also to product liability. Moreover, parts of the analysis apply more generally to compensation for non-performance within contract law, which of course shares essential characteristics with product liability. ${ }^{5}$

The main themes of the analysis concern the use of the negligence rule versus the use of strict liability, and whether, under the negligence rule, the standards of negligence for the two parties should be higher or lower than when both parties are fully informed. On the first theme, the negligence rule may do better than strict liability, since the discontinuity of the negligence rule might prevent IN from lowering her level of care in order to increase that of U. However, when IN cannot affect U's act of care, a rule that allocates the loss to IN is optimal. On the second theme, it turns out that general conclusions are difficult to draw for either of the two parties. Surprisingly, for example, when $U$ is the injurer and acts after IN, there are circumstances under which the court should apply a high standard of negligence for $\mathrm{U}$, just as it may under certain circumstances be optimal to lower the standard for IN below (and in other circumstances to raise it above) the first best first level. Nevertheless, two conclusions can be drawn that seem relevant from a policy perspective: First, when $U$ is the victim, there is no reason to hold him comparatively negligent as this will only diminish IN's incentive to take due care without affecting U's act of care (as U will not know about the standards). Second, in the prevalent case where IN is the injurer and acts first, and U understands the risk, it will be optimal for the court, under certain conditions, to set the standard of due care for IN

${ }^{5}$ Note, however, that in this interpretation, strict liability cannot be applied. 
at the first best level. IN will then take due care due to the discontinuity of the negligence rule, and $U$ will infer that IN will have taken due care, and will so take appropriate (first best) precautions himself.

The issue analyzed in this article should be distinguished from the question of whether legal ignorance should serve as an excuse, ${ }^{6}$ and from the question of how uncertainty of the law affects optimal standards. On the issue of legal ignorance as an excuse, it is not the information possessed by the individual but the information that a similar future party is likely to have that is relevant in the present context. The issue is not whether being ignorant should serve as an excuse; on the contrary, the implicit assumption behind the present analysis may be said to be that $U$ should not be required to invest in legal information, because doing so is too costly for him when he only takes part in the activity on a one-time or occasional basis. The issue is rather whether the standards themselves should be adjusted, either upwards or downwards, when one party is likely not to become aware of them.

As for the distinction between ignorance and uncertainty of the law, uncertainty has traditionally been modeled by assuming that an uncertain individual's beliefs can be represented by a probability distribution with a mean value equal to the actual standard. The present analysis, in contrast, assumes that U's probability distribution does not change with the actual standards. As the main effect of this difference, when U's beliefs are independent of the actual standards, the standards cannot (directly) affect U's behavior.

The following section relates the present article to existing literature. The third section introduces the model, while the fourth section analyzes which standards are optimal when IN acts first. In this section, two real-world cases illustrate the main findings. The fifth section analyzes the cases where IN dos not act first, while the sixth section discusses the case where $U$ is uninformed not only of legal standards but also of the risk of a loss. The article concludes with remarks and a summary of the main findings.

\footnotetext{
${ }^{6}$ The issue of when legal ignorance should be exculpatory arises in Kaplow (1990, section 5).
} 


\section{Related literature}

In the law and economics literature, the implications of legal ignorance have rarely been modeled. Yet, two articles address the issue of optimal regulation under onesided legal ignorance in a context similar to the present: Verkerke (2004) analyzes the issue of one-sided legal ignorance in the context of contract law, applying the idea of penalty default rules or standards (Ayres and Gertner (2001)). The idea is that when only one party (IN) is aware of the legal default standards governing their contractual relationship, the court can induce that party to communicate the efficient standards to $U$ by establishing default standards that are both inefficient and to U's advantage. In order not to be bound by inefficient default standards, IN must then inform $U$ of the standards that are to be applied instead of the default standards. According to Verkerke, this principle is not only of theoretical interest, but actually embedded in legal practice. While this is controversial (Posner (2006)), Verkerke's analysis raises the question of whether penalty default rules have the potential of eliminating the problem of one-sided, legal ignorance within contract. However, there are reasons to be skeptical in this regard. Communication of standards may be rendered difficult by several factors, e.g. by giving rise to false impressions: If the organizer of a dangerous activity mentions to the participants that she will be liable only if grossly negligent, the participants might interpret this to mean that the activity is very dangerous or that the organizer is irresponsible. More generally, it will often be too complex or time consuming to communicate standards of due care ${ }^{7}$ in such a way that $U$ will understand and trust the information, and it needs to be ex post verifiable that the communication of standards occurred. Thus, the issue remains how standards should be set under onesided legal ignorance, not only in a tort context but also when communication of standards between contracting parties cannot be brought about.

Kaplow (1990) analyzes how sanctions should be set when individuals are uncertain about whether one or another act is subject to sanctions. While not knowing which act is harmful, and hence subject to sanction, the individual is assumed to know the size of the sanction, and the authorities can, by changing the size of the sanction, affect not only the individual's incentive to undertake the act, but also his or her incentive to become informed of which act is harmful and hence subject to sanction. One insight from Kaplow's analysis is that it may be optimal to increase the sanction when the individual underestimates the probability that the act is in fact harmful (and

${ }^{7}$ Craswell (2004) emphasizes the difficulties of regulating a duty to inform that arise when more information is not always better and when information can be misleading rather than false. 
subject to sanction), and to raise the sanction when a higher sanction induces socially optimal investment in legal information. ${ }^{8}$

In contrast to the present analysis, Kaplow's concerns a situation where the authorities control a policy instrument that has a direct influence on the individual's behavior. In the present context, the size of damages can hardly be used as an instrument to influence the behavior of $U$. In tort and contract law, the sanction (certainly in civil law systems) is linked to the size of the loss. And even when damages can be either punitive or under-compensatory, $\mathrm{U}$ may be ignorant not only of the standard but also of the extent to which damages deviate from losses. Thus, the present analysis will assume that the authorities do not have a policy instrument by which they can directly affect U's behavior.

Finally, the connection between the doctrine of last clear chance (analyzed e.g. by Wittman (1981), Shavell (1983) and Miceli (2004)) and the present analysis is worth mentioning. The doctrine concerns the tort or contract situation where one party acts first and fails to take due care; the doctrine then requires the second mover to eliminate the risk, although doing so requires care that would not have been warranted if the first mover had acted with due care. The situation presents a trade-off between inducing the second mover to mitigate the risk, and inducing the first party to avoid creating the risk in the first place. The justification for the doctrine arises when there is some reason to expect the first mover to act without care. Thus, Wittman (1981) writes that "the first mover may fail to act for some reason" (p. 73), while Shavell (1983) adds "for some reason, such as the failure to perceive risk" (p. 591). The present analysis points to another rationale, namely that the first mover is unaware of or misperceives the negligence standard. In this case, a further rationale can be given for the doctrine, as the doctrine will not affect the first mover's incentives when the first mover is uninformed of the doctrine. To the extent that the second mover will be aware of the doctrine, it will provide optimal incentives.

\section{The model}

Define the following notation:

$i=(\bar{y}, \bar{x})$ : The set of standards for IN and $\mathrm{U}$, respectively. $\bar{y}$ belongs to the set $\Omega$, and $\bar{x}$ belongs to the set $\Omega$

$y(i)$ : The level of care exercised by IN as a function of the standards of due care, $y \in \Omega$

$x(y)$ : U's response function, i.e. U's level of care as a function of IN's care, $x \in \Omega$

${ }^{8}$ This general issue of the incentive to become informed is also analyzed in Kaplow and Shavell (1992)). 
$L$ : The size of the loss

$p(y, x)$ : The probability of loss as a function of care by the two parties

$y^{f b}, x^{f b}$ : The first best levels of due care, i.e. the levels of care that minimize

$y+x+p(y, x) L$

$\rho(i)$ : U's prior probability of the standards $i, \sum_{\Omega \times \Omega} \rho(i)=1$

$\eta(i, y)$ : U's updated probability of the standards $i$ contingent on $y, \sum_{\Omega \times \Omega} \eta(i)=1$

$f(y, x, i)$ : The share of the loss born by IN according to the comparative negligence rule when IN exercises care at level $y$, U exercises care at level $x$, and the standards are $i$. It is assumed that the parties can only share the loss; neither party can claim compensation for cost of precaution. ${ }^{9}$

Note that $f=0$ when IN takes due care, and that $f=1$ when $\mathrm{U}$ takes due care and

IN does not, whereas $f$ is between 0 and 1 when both take less than due care.

In the main part of the analysis $p(y, x), \rho(i), f(y, x, i)$ and $L$ are assumed to be common knowledge.

Bayesian updating is defined relative to IN's equilibrium strategy, i.e. if the set of standards compatible with the observed act is $\kappa$, then for any set of standards $i \in \kappa$, $\eta(i, y)=\frac{\rho(i)}{\sum_{j \in \kappa} \rho(j)}$. Furthermore, when IN chooses a strategy that is not part of her equilibrium strategy, $\mathrm{U}$ will be allowed to form any out-of-equilibrium belief concerning the underlying standards, except that IN's standard of care must be at least as high as the level of care chosen by IN. This restriction on the out-ofequilibrium beliefs is natural, as there is no reason for IN to choose a higher level of care than required.

A pure strategy equilibrium, $\left(\bar{y}^{*}, \bar{x}^{*}, y^{*}(\bar{y}, \bar{x}), x^{*}(y), \eta^{*}\right)$, must fulfill:

1. The equilibrium beliefs, $\eta^{*}(i, y)$, i.e. the probabilities that $\mathrm{U}$ attaches to the set of standards, $i$, when observing the act of care, $y$, are formed according to Bayes' rule in the manner just described.

2. For each $y, \mathrm{U}$ minimizes the sum of his cost of precaution and the part of the loss that he expects to bear, i.e. the response function, $x^{*}(y)$, is given by the minimization of $x+\sum_{i} \eta^{*}(i, y)(1-f(y, x, i)) p(y, x) L$.

${ }^{9}$ This possibility arises in Wittman's analysis of the last clear chance doctrine (1981). Within contract, costly mitigation can be compensated, but may be difficult to document. 
3. For any $i=(\bar{y}, \bar{x})$, IN's equilibrium response to the court's choice of standards, $y^{*}(\bar{y}, \bar{x})$, minimizes IN's cost of care plus expected liability, i.e. $y^{*}(\bar{y}, \bar{x})$ minimizes $y+f\left(y, x^{*}(y), i\right) p\left(y, x^{*}(y)\right) L$.

4. The court sets standards $\left(\bar{y}^{*}, \bar{x}^{*}\right)$ to minimize total expected costs of the ensuing equilibrium, i.e. the court minimizes

$y^{*}(\bar{y}, \bar{x})+x^{*}\left(y^{*}(\bar{y}, \bar{x})\right)+p\left(y^{*}(\bar{y}, \bar{x}), x^{*}\left(y^{*}(\bar{y}, \bar{x})\right) L\right.$ with respect to $(\bar{y}, \bar{x})$.

\section{Optimal standards of care when IN acts first}

\subsection{IN is the injurer}

This case is of particular interest, since IN will often be a specialized seller of a good or service, while $U$ will often be a buyer who does not take part in the activity or trade in the market sufficiently often to make it worthwhile for him to invest in information concerning standards. The following proposition establishes that the simple negligence rule dominates the comparative negligence rule.

\section{Proposition 1}

When the informed party is the injurer and acts first, it is a (weakly) dominant strategy for the court to apply the simple rather than the comparative negligence rule

\section{Proof:}

The main point is that if some level of care by IN can be implemented under the comparative negligence rule (with a standard of comparative negligence that is not set at its lowest possible level), then that level can also be implemented under the simple negligence rule. The proof proceeds by showing that if it is optimal for IN to take due care under the comparative negligence rule, it will also be optimal for IN to take due care under the simple negligence rule, and that if it is optimal for IN to take a lower level of care than required under the comparative negligence rule, that lower level can be implemented under the simple negligence rule by setting it equal to the standard of negligence. Since the response by $U$ can be assumed to be unaffected, any outcome that can be implemented under the comparative negligence rule can thus also be implemented under the simple negligence rule. Thus, consider first the case where IN adheres to the standard under the comparative negligence rule with standards equal to $(\bar{y}, \bar{x})$ : If $y^{*}=\bar{y}$, i.e. if IN adheres to the standard of due care, then for every $y<y^{*}, y^{*}<y+f\left(\bar{y}, \bar{x}, y, x^{*}(y)\right) p\left(y, x^{*}(y)\right) L$, since $y^{*}$ is better for IN than $y$. It will then also be the case that $y^{*}$ is better than $y$ under the simple negligence rule, since the condition then reads: $y^{*}<y+p(y, x(y)) L$, which must be fulfilled 
when the above inequality holds, since the share, $f$, is below or equal to 1 by assumption. Second, consider the case where the equilibrium choice of care, $y^{*}$, is less than the standard $\bar{y}$ under the comparative negligence rule. Then for every $y<y^{*}: y^{*}+f\left(\bar{y}, \bar{x}, y^{*}, x^{*}\left(y^{*}\right)\right) p\left(y^{*}, x\left(y^{*}\right)\right) L<y+f\left(\bar{y}, \bar{x}, y, x^{*}(y)\right) p\left(y, x^{*}(y)\right) L$ given that $y^{*}$ is preferred to $y$. If the standard of due care is then set equal to $y^{*}$ under the simple negligence rule, $y^{*}$ will still be preferred to any $y<y^{*}$, since under the simple negligence rule, the condition becomes $y^{*}<y+p\left(y, x^{*}(y)\right) L$, which is fulfilled when the above inequality holds, since $f\left(\bar{y}, \bar{x}, y^{*}, x^{*}\left(y^{*}\right)\right) p\left(y^{*}, x\left(y^{*}\right)\right) L>0$ and $f\left(\bar{y}, \bar{x}, y, x^{*}(y)\right) p\left(y, x^{*}(y)\right) L<p\left(y, x^{*}(y)\right) L$. QED.

The logic is simple: Lowering the standard for $U$ can have only the positive effect of increasing IN's incentive to adhere to the standard of due care set by the court - it does not decrease U's incentive as $U$ will not be aware of the lowering of the standard. Note that this logic applies generally, i.e. independently of the size of the sanction, of whether U understands the risk, etc.

The simple negligence rule strictly dominates the comparative negligence rule when IN expects U to take less than due care, and when IN takes less than due care because she expects to share the loss with U, although IN would avoid liability altogether by taking due care. Thus, the proposition mainly takes on importance when IN's incentive to take due care is insufficient, e.g. because uninformed victims will not raise claims, either because they will not become informed of the legal standard ex post or because a claim is not worth filing. In general, whenever there may a reason for strengthening IN's incentive, it becomes relevant that IN's incentive can be increased without affecting U's incentive.

It will now be argued that the court should set the standard of due care for IN at the first best level when a condition to be specified is fulfilled and U's beliefs are rational in a sense to be defined. First, it will be shown that when the condition is fulfilled, and U believes that IN has an incentive to take due care, that belief will be selfconfirming. Second, it will be demonstrated that when U holds the self-confirming belief, it will be optimal for the court to set the standard for IN at the first best level. Recall that $\tilde{x}(y)$ is the level of care that U will take when he believes that IN has taken due care equal to $y$, i.e. $\tilde{x}(y)$ minimizes $x+p(y, x) L$ with respect to $x$. The condition is that $y_{1}<y_{2}+p\left(y_{2}, \widetilde{x}\left(y_{2}\right)\right)$ when $y_{1}>y_{2}$, and concerns the importance of the discontinuity of the negligence rule. It simply states that it is worth it for IN to take due care, which rids her of all liability. The condition is likely to be fulfilled when losses are significant in relation to the cost of care, and when $U$ does not eliminate too much of the loss when reacting to IN's (lower) level of care. The following lemma can now be stated: 
Lemma: If $y_{1}<y_{2}+p\left(y_{2}, \tilde{x}\left(y_{2}\right)\right)$ when $y_{1}>y_{2}$, U's belief that IN has taken due care will be self-confirming in the sense that when $U$ holds the belief, it will be optimal for IN to take due care.

Proof of Lemma: When the standard of due care is $y_{1}$, the cost to IN from taking due care will be $y_{1}$, whereas if IN chooses some lower level of care, $y_{2}$, and U believes that this is the level required, IN's cost will be $y_{2}+p\left(y_{2}, \tilde{x}\left(y_{2}\right)\right)$. When the condition is fulfilled taking due care is then optimal for IN, which confirms U's belief. QED.

It follows that:

Proposition 2

When IN is the injurer and acts first and

1. U understands the risk,

2. For any $y_{1}$ and $y_{2}$ where $y_{1}>y_{2}: y_{1}<y_{2}+p\left(y_{2}, \tilde{x}\left(y_{2}\right)\right)$,

3. U holds the self-confirming belief that IN has acted with due care,

it is optimal for the court to set the standard for IN at the first best level, $y^{\text {tb }}$

Proof: When IN takes care equal to $y^{\text {tb }}$, U will expect IN to have taken due care and will therefore take care at that level which minimizes $x+p\left(y^{f b}, x\right) L$ with respect to $x$. This is the first best level of care, $x^{t b}$. Hence, the court can implement the first best outcome by setting the standard at the first best level. QED.

The question arises whether it remains optimal to set the first best standard for IN when $\mathrm{U}$ may form other out-of-equilibrium beliefs. It turns out that the answer is affirmative, although with a qualification. Thus, when the following two conditions hold, the first best outcome is the only possible equilibrium when the court sets the standard for IN at $y^{\text {tb }}$.

Condition 1: $y^{f b}<y+p(y, \tilde{x}(y)) L$ for $y<y^{f b}$.

Condition 2: When U believes that IN has acted with less than due care, U will take no more care than if he believes that IN has taken due care, since U will expect to share the loss with IN.

This second condition is not always fulfilled. The possibility exists that IN may take very little care in order to make $U$ believe that the standard of comparative negligence is very high, which might induce $U$ to conform to the very high standard 
in order to shift the whole loss to IN. However, a plausible (sufficient, not necessary) condition can be put on U's out-of-equilibrium beliefs, under which Condition 2 is fulfilled:

Condition 2': When U believes that the standard of due care for IN is higher than some level $\bar{y}^{\prime}$, then $\mathrm{U}$ also believes that the standard for himself cannot be higher than $\tilde{x}\left(\bar{y}^{\prime}\right)$, where $\tilde{x}\left(\bar{y}^{\prime}\right)$ minimizes $x+p\left(\bar{y}^{\prime}, x\right) L$ with respect to $x$.

The proof that these conditions are sufficient can be found in Appendix A.

Note that the conditions are sufficient but not necessary. For example, when IN's choice of care is dichotomous, it will never be optimal for the court to set a different standard for IN than the first best, as can be seen by simply noting that if the first best is the lower of the two possible care levels, it can be realized by only requiring low care by IN, and if first best is the higher of the two, it will never be strictly better to only require a low level of care (since this will of course not implement high care by IN).

It remains to be analyzed how standards should be set when Condition 1 above is not fulfilled. It is then challenging for the court to set the standard for IN, as there are circumstances in which the court should lower the standard for IN compared to the first best standard as well as other circumstances in which the court should raise the standard compared to the first best standard. The circumstances differ in terms of U's beliefs which are likely to be unknown to the court.

\section{Proposition 3}

When the informed party is the injurer and acts first, when the uninformed party knows the size of the risk, and when Condition 1 above is not fulfilled, it can be optimal for the court to set a lower or - under different circumstances - a higher standard than the first best for the informed party

\section{Proof: See Appendix B}

The logic can be explained as follows. On the one hand, it can be optimal for the court to set a lower than first best standard of due care when $U$ expects the standard for IN to be lower than first best. The point is that if the court sets the standard at first best, IN might take advantage of U's belief and exercise the lower level of care that $U$ expects, whereas if the court sets the standard at a lower level, namely in between the first best standard and what $\mathrm{U}$ expects, IN might wish to adhere to the standard set by the court rather than take the lower level of care that U expects. On the other hand, it can be optimal to set a higher standard than the first best when $U$ expects the standard to be higher than first best, for if the standard is then set equal to the first best, $\mathrm{U}$ might respond with too little care, believing that IN will be liable. If the standard is 
then raised, IN might still adhere to the higher standard, and U will then take adequate precautions, because $\mathrm{U}$ will no longer think that IN will be liable.

Proposition 3 implies that when $\mathrm{U}$ is aware of the risk, there is no clear presumption that the court should raise the standard for IN when U is legally ignorant, as one might perhaps be inclined to assume. The proposition illustrates that setting standards properly can be complex when U draws inferences based on how IN acts, and IN is aware of this.

Finally, it may be added that when the situation mentioned above arises where few claims are raised by the uninformed victims, it can become suboptimal for IN to take due care at the first best level, and it can then be shown to be potentially optimal for the court to lower the standard for IN, so as to make it worthwhile for IN to take due care.

Two real-world cases will now illustrate a tension between Proposition 1 and 2. While the first proposition directs attention away from how $\mathrm{U}$ acts and towards what IN could have done to prevent an accident, the other proposition provides a reason not to increase the standard for IN beyond the first best level.

\subsection{Two real world cases}

In a case ${ }^{10}$ decided by the Danish Supreme Court, a group of defrauded amateur investors sued a bank for not having told them that it had not inspected a financial project on which the investors based their loan from the bank. ${ }^{11}$ The project turned out to be fraudulent, and while the bank was not involved in the fraud, the bank's name was mentioned in the project in such a way that the investors could perhaps have inferred, as they claimed to have done, that the bank had lent its reputation to the project. In its verdict, the Supreme Court sent two signals: One to amateur investors that they must seek professional advice, and one to banks that they should inform their customers of their lack of involvement. (Ultimately, however, the Court did not hold the bank liable).

Applied to this case, the first proposition stresses that it may be futile from an incentive viewpoint to require amateur investors to seek professional advice or to

\section{${ }^{10}$ Court case U.2000.577/2H}

${ }^{11}$ Note that this is a duty to warn case; the issue is the extent to which I should be required to warn $U$, and how much vigilance should be required of $U$. Naturally, the duty to warn literature has already studied the issue of one-sided ignorance concerning the risk, but the issue here is that of one-sided ignorance concerning the duty for the seller (typically) to inform the buyer and the duty for the buyer to become informed. 
take some other precaution. To the extent that future amateur investors will not know the standards, these will not affect their behavior. The first proposition thus directs attention to the standard applied to IN. The second proposition poses the question of whether $U$ can be relied on to take proper precautions given the act of care by IN. However, to suppose that amateur investors will take proper precautions seems dubious, reflecting the more restrictive assumptions underlying the second proposition. The proposition relies on the investors believing that when the bank does not warn them, it must be because the bank is not required to do so, for otherwise the bank would have had an incentive to do it. If investors think in these terms, they will be on guard when the bank does not warn them, but investors might of course also be led to believe (with some probability) that the bank does not warn them, because it has checked the project and found nothing wrong. Hence, the assumption that the investors are aware of the existence of a risk or perceive it correctly may not hold. In essence, investors might not be guided by a standard requiring them to seek professional advice; some of them might therefore make mistakes and it can therefore be correct for the court to require the bank to warn customers although this is not the first best allocation of obligations. Hence, the first proposition arguably has greater relevance than the second in the context of this case, reflecting that it does not rely on $\mathrm{U}$ being aware of the risk.

As the second example, consider the case of the survival course mentioned in the introduction. In this case, the first proposition again appears to be relevant, as standards seem unlikely to become known by future participants. This raises the question as to the relevance of the second proposition. Arguably, most participants may indeed take proper precautions, realizing the danger of personal injury. Moreover, it may enter their minds that the organizer has an incentive to follow legal standards, and that they therefore bear the risk themselves. In other words, Proposition 2 is not without relevance in this case, and the standard for IN should possibly be set at the first best level (realistically taking into account, of course, that participants may make errors of judgment, etc.). ${ }^{12}$

\subsection{IN is the victim}

IN may well be the victim. For example, an insurance company may suffer losses when an insurance client fills in a questionnaire inaccurately; an employer may suffer

${ }^{12}$ The abstract standard tort model (in which no tort case ever arises in equilibrium) should not be taken too literally; both injurers and victims make mistakes and this should generally be born in mind when one sets standards; it can e.g. be optimal to require more care by one party when the other party is likely to make occasional mistakes. 
losses caused by an employee; or a landlord may suffer losses due to a tenant. This case will now be shown to differ markedly from the case where IN is the injurer. The equilibrium conditions for the case where IN is the potential victim and acts before $\mathrm{U}$ are analogous to those stated above for the case where IN is the injurer, except that the sharing rule distinguishes between the injurer and the victim. As the first result, it is (weakly) dominant for the court to apply the contributory rather than the comparative negligence rule.

\section{Proposition 4}

When IN acts first as the (potential) victim, it is a weakly dominant strategy for the court to apply the contributory negligence rule

\section{Proof: See Appendix C}

The point is that the contributory and comparative negligence lead to the same sharing of the loss when U acts with due care as well as when IN acts with due care while $U$ does not. A difference arises only when both IN and $U$ act with less than due care. In the latter case, the contributory negligence rule provides sharper incentives for IN to take due care, since she bears the whole loss when she acts with contributory negligence. Thus, the contributory negligence rule creates a similar discontinuity for the victim as the negligence rule does for the injurer, and this discontinuity increases the ability for the court to control IN's behavior when IN is the victim.

Note that it will only be strictly dominant to apply the contributory negligence rule, when IN is tempted to take less than due care, and U's response will be to also take less than due care. Thus, for the rule to be strictly dominant, it must be the case that IN's incentive to take due care under the comparative negligence rule is not sufficient, although by taking care, she will avoid sharing the loss with $U$. This is similar to the result above, that it is weakly optimal to apply the simple negligence rule when IN is the injurer.

An important difference to the case where IN is the injurer arises from the fact that when $U$ believes that IN will take due care, $U$ will not necessarily have an incentive to minimize $x+p(y, x) L$ with respect to $x$, as he does when he is the victim and expects IN not to be liable. If $U$ believes that the standard of due care for him is at a given level, he will tend to take that level of care in order to avoid liability. Thus, U's beliefs about standards come to play a greater role. This implies that it will generally be impossible for the court to implement the first best outcome, in contrast with the situation where IN is the injurer. Thus, when $x\left(y^{f b}\right) \neq \tilde{x}\left(y^{f b}\right)$, first best cannot be implemented, since when $y$ is at the optimal level, $x(y)$ will then not be. The best outcome which the court can hope to implement is that which minimizes 
$y+x(y)+p(y, x(y)) L$, where $x(y)$ is U's response function. Note that there may be more than one equilibrium in the game between IN and U, and so there may be more than one response function, depending on U' initial beliefs. The following proposition holds for any such equilibrium response function, $x(y)$, assuming that when the court seeks to implement $\hat{y}$, a choice of care exists for $\mathrm{U}$ that is higher than $x(\hat{y})$ such that the standard can be higher than $x(\hat{y})$ :

\section{Proposition 5}

When IN is the potential victim and acts first, the outcome, $\hat{y}$, which minimizes $y+x(y)+p(y, x(y)) L$ can be implemented when $\hat{y}<y+p(y, x(y)) L$ for $y<\hat{y}$ by setting the standard of contributory negligence equal to $\hat{y}$, and the standard of negligence for $U$ above $x(\hat{y})$

Proof: Consider whether IN should choose $y \neq \hat{y}$. When IN chooses $\hat{y}$, her costs are $\hat{y}$, since she takes due care, whereas $\mathrm{U}$ will be negligent given that the standard for $\mathrm{U}$ is set above $x(\hat{y})$. When IN chooses $y>\hat{y}$, her cost will of course be higher than $\hat{y}$. When IN chooses $y<\hat{y}$, she will be negligent, and will hence, irrespective of U's negligence, bear the cost, $y+p(y, x(y)) L$, due to the nature of the contributory negligence rule. QED

The idea is to hold $\mathrm{U}$ negligent such that IN will have a strong incentive to adhere to the standard of contributory negligence in order to shift the whole loss to U. Note the perhaps surprising implication that $U$ should be held liable in equilibrium; outside equilibrium IN should bear the whole loss whenever IN has violated the standard of contributory negligence. Note also, however, that the court must know not only relative costs and benefits of precaution, but also U's response function which depends on U's beliefs, to set optimal standards in this case.

\section{Optimal standards when IN does not act first}

\subsection{IN is the injurer}

When IN is the injurer and acts after or at the same time as $U$, the act of care by $U$ is determined by U's beliefs in a Bayesian Nash-equilibrium, and is outside the influence of both the court and IN. The court should then concentrate on inducing IN to act optimally given the act of care by $\mathrm{U}$. This can be done by never holding $\mathrm{U}$ 
comparatively negligent, and by setting such a high standard of due care for IN that adhering to it is never optimal for IN, i.e. to essentially hold IN strictly liable ${ }^{13}$ (without contributory negligence). IN will then minimize $y+p(y, x) L$ given $x$, which is socially optimal. Proposition 6 follows directly:

\section{Proposition 6}

When IN is the injurer but does not act first, the rule of strict liability without contributory negligence is optimal

Naturally, Proposition 6 applies also to the case where IN acts first but $U$ does not observe IN's level of care; it applies, in short, whenever IN cannot influence U's act of care.

When it is not possible to hold IN strictly liable, the optimal standard for IN may be either higher or lower than first best. For example, when $U$ will respond with too much care (e.g. because he is uncertain of what is required of him (Calfee and Craswell (1986); Shavell (1987))), the optimal standard for IN will be lower than first best, when care by the two parties are substitutes rather than complements. ${ }^{14}$ However, for reasons already established, it will generally be optimal not to hold $U$ liable as doing so will only undermine IN's incentive to take due care.

\subsection{IN is the victim}

When $\mathrm{U}$ acts first as the injurer, the court should, in theory, never hold $\mathrm{U}$ liable, as never holding $U$ liable will induce the correct response from IN, which is to minimize the total costs given the act by $\mathrm{U}$, i.e. to minimize $y+p(y, x) L$ given $x$. This is what IN will do if IN does not expect $U$ to be liable, whereas if IN expects $U$ to be liable, IN might take too little care given the act of care by $\mathrm{U}$. Thus, a very lenient negligence standard (or the absence of liability) will in principle be optimal when $U$ acts first as the injurer.

\section{Proposition 7}

When IN is the victim and acts after $U$, the absence of liability for $U$ is optimal

\footnotetext{
${ }^{13}$ Again, strict liability can be phrased as a negligence rule with a very high standard, which avoids the issue of whether $U$ understands the choice of rule (rather than of standard).

${ }^{14}$ See Lando (2007).

16
} 
Note the contrast between Propositions 6 and 7: When $U$ is the injurer and acts second, $\mathrm{U}$ should always be held liable, whereas if $\mathrm{U}$ is the injurer and acts first, he should never be held liable.

Naturally, Proposition 7 is mainly relevant when $\mathrm{U}$ takes too little care. When $\mathrm{U}$ takes too much care, as he may well do when uncertain about the standard, IN will know that she bears the residual risk and will hence act appropriately. It is then not necessary (although still optimal within the simplified model) to set a low standard for $\mathrm{U}$.

\section{6. $U$ is uninformed also of the risk}

So far, the analysis has revealed that when U's act of care is independent of IN's, i.e. when $\mathrm{U}$ does not act after IN, it is optimal for the court to put as much of the loss on IN as possible in order to induce IN to minimize total costs. This follows from Propositions 6 and 7 . This result generalizes to cases where $U$ does not expect there to be any risk of a loss (and where a duty to warn is ineffective), and where $\mathrm{U}$ hence acts without care, regardless of IN's act of care. This, of course, is consistent with the prevailing rule that the seller is strictly liable for a defective product, i.e. for a loss that the buyer could not reasonably have expected. However, the possibility exists that the act of care by IN may alert $U$ to the existence of a risk. If so, U's response function will be sensitive to the act performed by IN, in which case the advantage of the negligence rule over strict liability in controlling IN's act of care may come into play. Thus, when IN is strictly liable, she might induce too much care on the part of $\mathrm{U}$, whereas the court can (when well-informed) set the standard for IN at the optimal level given U's response function. Note, however, that when IN is the injurer and acts first, it may not be optimal to set the standard of due care for IN at the first best level when $U$ is uninformed of the risk, for $U$ may not be alerted to the risk when IN takes first best care. Thus, the court should possibly set a standard of due care for IN at a higher level than the first best in order to induce IN to reveal the existence of a risk to U. In other words, the possibility that $U$ is uninformed of the risk, and that it may not be a simple solution to simply require IN to inform $U$ of the risk, has implications only for the cases where IN acts first, and then in the direction of increasing the standard of due care required of IN either as a victim or as an injurer.

\section{Remarks}

Two remarks will be made. As the first remark, it can sometimes be clear to everyone involved, from conventional fairness reasoning or from the logic of cost minimization, what both parties ought to do to avoid an accident. Courts may wish to adhere to such standards, either to be fair to the litigant in the actual case, or because 
the court hopes that the general policy of the court to require such acts to be taken can become known to people. Two comments will be made in this regard: First, whether the general policy or principle will become known to people acting outside their profession can be doubtful. In many if not all areas of law, most people know very little about how the legal system operates. ${ }^{15}$ Second, it is often not clear which standards sustain appropriate norms; this is often a question of judgment, of weighing a disparate set of costs, and, when the weighing is less obvious, both the fairness and the learning argument is weaker. Still, when applicable, these arguments should be weighed against the incentive arguments analyzed in this article; for example, they may strengthen the rationale for the court to maintain first best standards despite the presence of one-sided legal ignorance, but constrain the applicability of the finding that IN should bear the loss whenever U's act of care is independent of IN's. As the second remark, people may not know the nature of the negligence rule and will not draw the inference that IN has an incentive to act with due care to escape liability. However, note that when $U$ is the victim, acts after IN, and knows the risk, he should take appropriate care whenever he does not expect to be able to hold IN liable. It seems realistic to assume that some fraction of those who are ignorant of the workings of the legal system will not expect to be able to sue the more professional counterpart, and the result that the standard for IN should be set at the first best level can then still hold. Moreover, the idea that the negligence rule may dominate strict liability when IN acts first applies whenever U's act of care varies in some way with IN's, and IN cannot be made to compensate U for a too high level of care induced by IN's low level of care. For this idea to apply, it is not essential that U's response function is based on a rational inference.

\section{Summary}

One way of summarizing the main findings is by contrasting them with the simple logic that the court should let the informed party bear the loss, since the court can only have an effect on the informed party's behavior, and should hence seek to maximize this effect. The error in this view is that when the informed party acts first, she may not take the correct level of care if she realizes that she can influence the uninformed party's act of care. She will then not take into account the higher cost of precaution that she may cause the other party to bear by lowering her own level of care (assuming that the informed party cannot be made liable for the uninformed party's higher cost of precaution). Therefore, the negligence rule may be preferable, either the simple negligence rule when the informed party is the injurer, or the contributory negligence rule, when she is the victim. Moreover, in the former case of

${ }^{15}$ See Ellickson (1991). 
simple negligence, the optimal standard may be the first best standard, which induces the first best outcome under certain not very restrictive conditions. In the latter case of contributory negligence, it may, contrary to the intuition that the informed party should bear all the risk, be optimal to always hold the uninformed party negligent in order to sharpen the informed party's incentive to adhere to the standard of contributory negligence. However, when the informed party does not act first, and hence cannot influence the act of care by the uninformed party, or if for some other reason U's act is independent of IN's, the logic of allocating the loss to the informed party applies. The court should then apply strict liability when the injurer is the informed party and should never hold the uninformed liable when the injurer is the uninformed party. When strict liability is not an option for the court, and the court must set negligence standards within reasonable bounds, it may be optimal for the court to either increase or decrease the standard for the informed party as compared with the first best standard. This applies both when the informed party can affect the care level of the uninformed and when she cannot; there is thus no presumption, within the realm of the negligence rule, that the standards should be increased for the informed party, as long as is the uninformed party can be assumed to understand the risk. However, when the uninformed party is the victim, he should not be held comparatively negligent (or the standard should in practice be low), as letting him bear part of his own loss will have no effect on his act of care, but will diminish the incentive for the informed party to take care.

\section{Appendix A}

Proof that when the court sets the standard at the first best level and the following two conditions hold:

Condition 1: $y^{f b}<y+p(y, \tilde{x}(y)) L$ for $y<y^{f b}$

Condition 2': When U believes that the standard of due care for IN is higher than some level $\bar{y}^{\prime}$, then $\mathrm{U}$ also believes that the standard for him cannot be higher than $\tilde{x}\left(\bar{y}^{\prime}\right)$, where $\tilde{x}\left(\bar{y}^{\prime}\right)$ minimizes $x+p\left(\bar{y}^{\prime}, x\right) L$ with respect to $x$

the only perfect Bayesian equilibrium is the first best outcome.

The proof is by contradiction: Consider the possibility that the court sets the standard at $y^{f b}$, and that an equilibrium where $y<y^{f b}$ then arises in the game between IN and $\mathrm{U}$. Two possibilities then emerge. Either $\mathrm{U}$ believes the standard is $y$, or $\mathrm{U}$ believes that the standard is higher than $y$ (U can safely exclude that IN has chosen a higher level of care than the standard). If $U$ believes that the standard is $y$, i.e. that IN has taken due care, $\mathrm{U}$ will respond by $\tilde{x}(y)$, and the total cost to IN will then be 
$y+p(y, \tilde{x}(y)) L$. This is higher than the cost of exercising first best care when Condition 1 is fulfilled, and so this contradicts that $y$ is an equilibrium choice for IN. If $U$ believes the standard for IN is higher than $y$, i.e. if $U$ expects IN to be liable, $\mathrm{U}$ will take a level of care that cannot be higher than $\tilde{x}(y)$, since U expects IN to bear part of the loss, and $\tilde{x}(y)$ is U's response when $\mathrm{U}$ expects to bear the whole loss. $\mathrm{U}$ might wish to take a higher level of care than $\tilde{x}(y)$ if he would thereby expect to take due care and put the whole loss on IN, but Condition 2 precludes that $U$ believes the standard of due care for $\mathrm{U}$ to be higher than $\tilde{x}(y)$, so U will not take a higher level of care than $\tilde{x}(y)$. Given that $\mathrm{U}$ takes care at level $x^{\prime} \leq \tilde{x}(y)$, then $y+p\left(y, x^{\prime}\right) L \geq y+p(y, \tilde{x}(y)) L$, in which case $y^{f b}<y+p\left(y, x^{\prime}\right) L$ when $y^{f b}<y+p(y, \tilde{x}(y)) L$. Again, it is then better for IN to choose $y^{f b}$. This contradicts that there is an equilibrium where IN chooses $y<y^{\text {fb }}$ when the two conditions are fulfilled. QED.

\section{Appendix B}

Proof of Proposition 3, that it may be optimal either to lower the standard or to raise it compared with first best when Condition 1 is not fulfilled.

The following example shows that it may be optimal for the court to set a standard lower than first best. Thus, consider the game shown in Table 1 below, where the informed party chooses between three levels of care, $0,1 / 2$, or 1 (as parameterized by the cost of exercising that level of care), and the uninformed party only chooses between two levels of care, 0 or 1 . The entries in the table are the expected losses, $p(y, x) L$, resulting from the alternative care levels selected by the two parties.

\begin{tabular}{|c|c|c|}
\hline $\mathbf{x}$ & 1 & 0 \\
\hline 1 & 0 & $3 / 4$ \\
\hline $1 / 2$ & 0.6 & 1.28 \\
\hline 0 & 0.8 & 3.1 \\
\hline
\end{tabular}

Table 1 
The first best outcome is for IN to exercise level 1 and for $U$ to exercise level 0 , the total cost is then 1.75, which is the lowest attainable cost. It will now be shown that when $\frac{\rho(\bar{y}=1)}{\rho(\bar{y}=0)}<1.2$ and $U$ assumes the standard of comparative negligence is $\bar{x}=0$, it is optimal for the court to set the standard $\bar{y}=1 / 2$.

Proof: Under the said conditions, the equilibrium is the following:

$y^{*}(1)=0 ; \quad y^{*}(1 / 2)=1 / 2 ; \quad y^{*}(0)=0$ and

$x^{*}(y=1)=0 ; x^{*}(y=1 / 2)=0 ; x^{*}(y=0)=1$

$\eta^{*}(\bar{y}=1, y=0)=\frac{\rho(\bar{y}=1)}{\rho(\bar{y}=0)+\rho(\bar{y}=1)}, \eta^{*}(\bar{y}=1, y=0)=1-\frac{\rho(\bar{y}=1)}{\rho(\bar{y}=0)+\rho(\bar{y}=1)}$,

$\eta^{*}(\bar{y}=1 / 2, y=1 / 2)=1$. Out-of-equilibrium beliefs can be anything, with the said restriction.

To verify that this is an equilibrium, consider U's responses first:

When $y=1$, $\mathrm{U}$ must form an out-of-equilibrium belief. As mentioned above, the only reasonable belief is that the standard is high, i.e. $\bar{y}=1$, since IN will only take care at level $y=1$ if the standard is $\bar{y}=1$. If the standard is $\bar{y}=1$, $\mathrm{U}$ will minimize his cost by choosing $x=0$, since $3 / 4<1$, regardless of the standard of comparative negligence. When $y=1 / 2$, the standard must be $\bar{y}=1 / 2$, since, according to the postulated equilibrium, this level of care is chosen only when the standard is $\bar{y}=1 / 2$, whereas IN chooses to exercise care equal to $y=0$ when the standard is different from $1 / 2$. When the standard for IN is $\bar{y}=1 / 2$, U should optimally choose $x=0$, again regardless of the standard of comparative negligence, as $1.28<1.6$. When $y=0$, the standard is either $\bar{y}=1$ or $\bar{y}=0$. If it is $\bar{y}=1$, U's cost from choosing $x=1$ is 1 , since the standard of comparative negligence cannot be higher than $\bar{x}=1$, while the cost to $U$ from choosing $x=0$ is 0 given the assumption that $U$ expects the standard of comparative negligence to be $\bar{x}=0$. If the standard is $\bar{y}=0$, U's costs are $1+0.8$ from choosing $x=1$ but 3 from choosing $x=0$. The ex-post probability, $\eta(0)$, of the standard being $\bar{y}=0$, is: $\frac{\rho(\bar{y}=0)}{\rho(\bar{y}=0)+\rho(\bar{y}=1)}$, while the probability is $\frac{\rho(\bar{y}=1)}{\rho(\bar{y}=0)+\rho(\bar{y}=1)}$ that the standard is $\bar{y}=1$. Hence, the expected cost for $\mathrm{U}$ of choosing $x=1$ is $\frac{\rho(\bar{y}=1)}{\rho(\bar{y}=0)+\rho(\bar{y}=1)} 1+\frac{\rho(\bar{y}=0)}{\rho(\bar{y}=0)+\rho(\bar{y}=1)}(1+0.8)$, while the 
expected cost from choosing $x=0$ is $\frac{\rho(\bar{y}=1)}{\rho(\bar{y}=0)+\rho(\bar{y}=1)} 0+\frac{\rho(\bar{y}=0)}{\rho(\bar{y}=0)+\rho(\bar{y}=1)} 3$. Hence, the expected cost from choosing $x=1$ is lower when $\frac{\rho(\bar{y}=1)}{\rho(\bar{y}=0)}<1.2$.

Next, consider IN's incentives when U's responds by taking high care only when IN chooses the lowest possible level of care. The incentives depend on the standard $\bar{y}$ but not on the standard $\bar{x}$, as will be pointed out. If the court sets a standard $\bar{y}=1$, this provides IN with an incentive to choose $y=0$, since the cost of her liability is then only .8 regardless of the standard of comparative negligence. If the court sets the standard equal to $\bar{y}=1 / 2$, IN will choose $y=1 / 2$ at a cost of $1 / 2$, since if IN chooses $y=0$, the cost to her will be .8 regardless of the standard of comparative negligence. Finally, if the court sets a standard equal to $\bar{y}=0$, IN will naturally choose $y=0$. Given that IN will choose $y=0$ when $\bar{y}=1$, while IN will choose $y=1 / 2$ when $\bar{y}=1 / 2$, the optimal standard is $\bar{y}=1 / 2$, since the total social cost of 1.78 is lower for the standard $\bar{y}=1 / 2$ than the total cost of 1.8 for the standard $\bar{y}=1$ (and the social cost of the standard $\bar{y}=0$ is also 1.8). QED.

Second, it will be shown that it can be optimal for the court to raise the standard in comparison to first best.

Again, an example will suffice. Consider the following expected losses arising from an alternative care level (parameterized again by care costs) as shown in Table 2:

\begin{tabular}{|c|c|c|c|}
\hline $\mathbf{x}$ & 2 & 1 & 0 \\
\hline 3 & 0 & $1 / 2$ & 1 \\
\hline 1 & $1 / 4$ & $5 / 6$ & $7 / 4$ \\
\hline 0 & $1 / 2$ & 2 & 10 \\
\hline
\end{tabular}

Table 2

The first best outcome is $(y, x)=(0,2)$, since no other combination of care levels achieves a total cost of less than $2 \frac{1}{2}$. However, it will now be proven that: 
When U's ex-ante believes that he will not be comparatively negligent and his beliefs concerning the standards for IN satisfy the following condition:

$2 \rho(\bar{y}=3)>\rho(\bar{y}=0)>\rho(\bar{y}=3) / 7$, then the equilibrium strategies are:

$y^{*}(3)=0 ; y^{*}(1)=1 ; y^{*}(0)=0, x^{*}(y=3)=0 ; x^{*}(y=1)=0 ; x^{*}(y=0)=1$, the outcome is $y=1$ and $x=2$, and the standards $\bar{y}=1$ and $\bar{x}=0$ are optimal.

It will first be proven that the strategies of IN and $\mathrm{U}$ are equilibrium strategies given that $\bar{x}=0$. Consider first U's response when IN chooses $y=0$ :

Given that IN chooses $y=0$ both when the standard is $\bar{y}=3$ and when it is $\bar{y}=0$, Bayesian updating implies that the ex post probability of the standard being $\bar{y}=3$ when $y=0$ equals $\frac{\rho(\bar{y}=3)}{\rho(\bar{y}=3)+\rho(\bar{y}=0)}$, while the probability that it is $\bar{y}=0$ equals $\frac{\rho(\bar{y}=0)}{\rho(\bar{y}=3)+\rho(\bar{y}=0)}$. Given these probabilities, the costs to $\mathrm{U}$ of choosing 2,1 or 0 can now be compared, given that $\mathrm{U}$ assumes he is never held comparatively negligent. The cost to $\mathrm{U}$ of choosing 2 equals:

$\frac{\rho(\bar{y}=3)}{\rho(\bar{y}=3)+\rho(\bar{y}=0)} 2+\frac{\rho(\bar{y}=0)}{\rho(\bar{y}=3)+\rho(\bar{y}=0)}(2+1 / 2)$. The cost of choosing 1 equals: $\frac{\rho(\bar{y}=3)}{\rho(\bar{y}=3)+\rho(\bar{y}=0)} 1+\frac{\rho(\bar{y}=0)}{\rho(\bar{y}=3)+\rho(\bar{y}=0)}(1+2)$. The cost of choosing 0 equals: $\frac{\rho(\bar{y}=3)}{\rho(\bar{y}=3)+\rho(\bar{y}=0)} 0+\frac{\rho(\bar{y}=0)}{\rho(\bar{y}=3)+\rho(\bar{y}=0)}(0+10)$. Hence, U prefers 1 over 2 when: $\frac{\rho(\bar{y}=3)}{\rho(\bar{y}=3)+\rho(\bar{y}=0)} 2+\frac{\rho(\bar{y}=0)}{\rho(\bar{y}=3)+\rho(\bar{y}=0)}(2+1 / 2)>$ $\frac{\rho(\bar{y}=3)}{\rho(\bar{y}=3)+\rho(\bar{y}=0)} 1+\frac{\rho(\bar{y}=0)}{\rho(\bar{y}=3)+\rho(\bar{y}=0)}(1+2)$; i.e. when $2 \rho(\bar{y}=3)>\rho(0)$. $\mathrm{U}$ prefers 1 to 0 when:

$\frac{\rho(\bar{y}=3)}{\rho(\bar{y}=3)+\rho(\bar{y}=0)} 0+\frac{\rho(\bar{y}=0)}{\rho(\bar{y}=3)+\rho(\bar{y}=0)}>\frac{\rho(\bar{y}=3)}{\rho(\bar{y}=3)+\rho(\bar{y}=0)} 1+$ $\frac{\rho(\bar{y}=0)}{\rho(\bar{y}=3)+\rho(\bar{y}=0)}(1+2)$, i.e. when $7 \rho(\bar{y}=0)>\rho(\bar{y}=3)$.

Thus, $\mathrm{U}$ will respond to $y=0$ with 1 when $2 \rho(\bar{y}=3)>\rho(\bar{y}=0)>\rho(\bar{y}=3) / 7$ when he assumes that he will not be held comparatively negligent.

Next, consider U's response to 1 . If IN chooses 1 , U can infer that this must be the standard (since, in equilibrium, 1 is only chosen by IN when 1 is the standard), and $U$ will hence choose 0 , which minimizes his given his belief about the standard of comparative negligence. Finally, if IN chooses 3, the optimal choice for $U$ is clearly 23 
0 , since $\mathrm{U}$ will realize that the standard must be $\bar{y}=3$ and that $\mathrm{U}$ will hence carry the loss; 2 is then the lowest achievable loss.

Consider, in turn, the strategy by IN given U's response function. Three possibilities should be compared under the assumption that $2 \rho(\bar{y}=3)>\rho(\bar{y}=0)>\rho(\bar{y}=3) / 7$ when $\mathrm{U}$ responds as just indicated:

1. The standard is $\bar{y}=3$ : It is then better for IN to choose 0 than 3 , since the response to 0 will be 1 , imposing a total cost of 3 on IN. It is also better for IN to choose 0 than 1 , since the total cost to 1 is $2 \frac{3}{4}$, while the total cost to 0 is 2 .

2. When the standard is $\bar{y}=1$, it is better for IN to choose 1 than 0 , since the cost of choosing 1 is 1 when $\bar{y}=1$ is the standard, while the cost of choosing 0 is 2 , since the response to 0 is 1 .

3. When the standard is $\bar{y}=0$, IN will choose 0 , since there is no reason to choose a higher level of care than the standard.

This verifies the stated equilibrium in the game between IN and U. It remains to be shown that it is optimal for the court to choose the standards $(\bar{y}, \bar{x})=(1,0)$, which lead to the outcome where IN chooses 1 and $\mathrm{U}$ chooses 0 with a total social cost of $2 \frac{3}{4}$. To see this, note that the outcome is the second best outcome. Hence, for other standards to be preferable, they must realize the first best outcome. However, that the first best cannot be realized can be seen as follows. The first best outcome requires that U responds to IN's act of $y=0$ by taking the act $x=2$.

However, when $\mathrm{U}$ responds in this way, it becomes optimal for IN to choose $y=0$ also when the standard is $\bar{y}=1$ or $\bar{y}=3$. Hence, there must then be complete pooling, which means that $U$ cannot derive any information from IN's act. When $U$ ex ante believes that $\bar{x}=0$, $\mathrm{U}$ will then rather choose $x=1$ than $x=2$, when $(2+1) \rho(\bar{y}=0)+(1)(\rho(\bar{y}=1)+1 \rho(\bar{y}=3)<(2+1 / 2) \rho(\bar{y}=0)+2(\rho(\bar{y}=1)+\rho(\bar{y}=3))$, i.e. when $\rho(\bar{y}=0)<2(\rho(\bar{y}=1)+\rho(\bar{y}=3))$ which is fulfilled when $2 \rho(\bar{y}=3)>\rho(\bar{y}=0)$. Hence, the first best cannot be achieved, and the standards chosen must then optimal. QED.

Appendix C

Proof that the rule of contributory negligence is weakly dominant when IN is the victim and acts first.

It will be shown that whatever can be implemented by the comparative negligence rule can be implemented also by the contributory negligence rule. 
Consider an equilibrium under the comparative negligence rule in which $y^{\prime}$ is implemented and where the standard of comparative negligence is $\bar{y}$. It will be shown that when $y^{\prime}$ is preferred to some other $y^{\prime \prime}$ under comparative negligence, it will also be preferred under contributory negligence when the standard under contributory negligence is set equal to $y^{\prime}$. There are four cases to consider:

A: $x\left(y^{\prime}\right)$ and $x\left(y^{\prime \prime}\right)$ are both below the standard of due care for $\mathrm{U}$.

B: $x\left(y^{\prime}\right)$ is below the standard of due care while $x\left(y^{\prime \prime}\right)$ is not.

C: $x\left(y^{\prime}\right)$ is above or equal to the standard of due care while $x\left(y^{\prime \prime}\right)$ is below.

$\mathrm{D}$ : Both are above or equal to the standard of due care for $\mathrm{U}$.

Case A: $y^{\prime}$ cannot be above $\bar{y}$, since it will not be worthwhile for IN to take more than due care when due care is sufficient to put the whole loss on U. There are two sub-cases to consider:

Case 1: $y^{\prime}=\bar{y}$

Case 2: $y^{\prime}<\bar{y}$

In Case 1, there are two further sub-cases: Case 1a: $y^{\prime \prime}<y^{\prime}$ and Case 1b: $y^{\prime \prime} \geq y^{\prime}$. Consider first Case 1a: Since $y$ ' is the preferred choice under comparative negligence, and the cost to IN when she takes the level of care $y^{\prime}$ is equal to $y^{\prime}$ as $\mathrm{U}$ bears the loss when $\mathrm{U}$ is negligent and IN is not, it must hold that:

$y^{\prime}<y^{\prime \prime}+\left(1-f\left(y^{\prime \prime}, x\left(y^{\prime \prime}\right), \bar{y}, \bar{x}\right) p\left(y^{\prime \prime}, x\left(y^{\prime \prime}\right)\right) L\right.$, where $1-f$ is the share born by IN under the comparative negligence rule. Under the contributory negligence rule, when the standard of due care is $y^{\prime}$, the cost to IN from taking the level of care $y^{\prime}$ is $y^{\prime}$ given that the response from $\mathrm{U}$ is the same as under comparative negligence, i.e. the negligent $x\left(y^{\prime}\right)$, while the cost for IN from taking the level of care $y^{\prime \prime}<y^{\prime}$ equals $y^{\prime \prime}+p\left(y^{\prime \prime}, x\left(y^{\prime \prime}\right)\right) L$ given that IN bears the whole loss when negligent under the contributory negligence rule. When $y^{\prime}<y^{\prime \prime}+\left(1-f\left(y^{\prime \prime}, x\left(y^{\prime \prime}\right), \bar{y}, \bar{x}\right) p\left(y^{\prime \prime}, x\left(y^{\prime \prime}\right)\right) L\right.$, it follows that $y^{\prime}<y^{\prime \prime}+p\left(y^{\prime \prime}, x\left(y^{\prime \prime}\right)\right) L$, since $1-f \leq 1$. Hence, when $y^{\prime}$ is preferred to $y^{\prime \prime}$ under the comparative negligence rule, the case is the same under the contributory negligence rule.

Consider then Case 1b: When $y^{\prime \prime}>y^{\prime}$ and $y^{\prime}=\bar{y}$ under both rules, and $\mathrm{U}$ is always negligent, the whole loss will be on $\mathrm{U}$ under both rules when IN chooses $y^{\prime}$, which will hence clearly be preferable to choosing $y^{\prime \prime}>y^{\prime}$ under both rules.

In Case 2, where $y^{\prime}<\bar{y}$, there are again two sub-cases: Case 2a: $y^{\prime \prime}<y^{\prime}$ and Case 2b: $y^{\prime \prime} \geq y^{\prime}$.

Case 2a: Since $y^{\prime}$ is the preferred choice under comparative negligence, it must hold that $y^{\prime}+\left(1-f\left(y^{\prime}, x\left(y^{\prime}\right), \bar{y}, \bar{x}\right) p\left(y^{\prime}, x\left(y^{\prime}\right)\right) L^{\prime}<y^{\prime \prime}+\left(1-f\left(y^{\prime \prime}, x\left(y^{\prime \prime}\right), \bar{y}, \bar{x}\right) p\left(y^{\prime \prime}, x\left(y^{\prime \prime}\right)\right) L\right.\right.$.

Under the contributory negligence rule with the standard of contributory negligence equal to $y^{\prime}$, the condition becomes $y^{\prime}<y^{\prime \prime}+p\left(y^{\prime \prime}, x\left(y^{\prime \prime}\right)\right) L$ as IN bears no cost when not 
negligent, and IN bears the whole cost when negligent at $y$ ". That $y^{\prime}<y^{\prime \prime}+p\left(y^{\prime \prime}, x\left(y^{\prime \prime}\right)\right) L$ when:

$y^{\prime}+\left(1-f\left(y^{\prime}, x\left(y^{\prime}\right), \bar{y}, \bar{x}\right) p\left(y^{\prime}, x\left(y^{\prime}\right)\right) L^{\prime}<y^{\prime \prime}+\left(1-f\left(y^{\prime \prime}, x\left(y^{\prime \prime}\right), \bar{y}, \bar{x}\right) p\left(y^{\prime \prime}, x\left(y^{\prime \prime}\right)\right) L\right.\right.$ can be seen by noting that when:

$y^{\prime}+\left(1-f\left(y^{\prime}, x\left(y^{\prime}\right), \bar{y}, \bar{x}\right) p\left(y^{\prime}, x\left(y^{\prime}\right)\right) L^{\prime}<y^{\prime \prime}+\left(1-f\left(y^{\prime \prime}, x\left(y^{\prime \prime}\right), \bar{y}, \bar{x}\right) p\left(y^{\prime \prime}, x\left(y^{\prime \prime}\right)\right) L\right.\right.$, then

$y^{\prime}<y^{\prime \prime}+\left(1-f\left(y^{\prime \prime}, x\left(y^{\prime \prime}\right), \bar{y}, \bar{x}\right) p\left(y^{\prime \prime}, x\left(y^{\prime \prime}\right)\right) L\right.$, and then $y^{\prime}<y^{\prime \prime}+p\left(y^{\prime \prime}, x\left(y^{\prime \prime}\right)\right) L$, since $1-f \leq 1$.

Case 2b: When $y^{\prime \prime}>y^{\prime}$ and $y^{\prime}$ is the standard of contributory negligence, and $\mathrm{U}$ is negligent, $y^{\prime}$ must be preferred to $y^{\prime \prime}$ under the contributory negligence rule, since IN will bear no part of the loss when she acts with due care (and U does not). This ends the proof of Case $\mathrm{A}$.

Cases B, C and D follow the same logic. The calculations are almost identical to the ones just carried out, and are available from the author upon request.

\section{References}

Ayres, I. and Gertner, R., 2001. Filling Gaps in Incomplete Contracts: An Economic Theory of Default Rules, in E. A. Posner: Law and Economics. International Library of Essays in Law and Legal Theory. Second Series. Aldershot, U.K.; Burlington, VT and Sydney, Ashgate Dartmouth, pp. 5-48.

Cooter, R., 2000. Three Effects of Social Norms on law: Expression, Deterrence, and Internalization, vol. 79 Oregon Law Review, pp 1-22.

Craswell, R., 2006. Taking Information Seriously: Misrepresentation and Nondisclosure in Contract Law and Elsewhere, vol. 92 Virginia Law Review, p. 565.

Craswell, R. and Calfee, C., 1986. Deterrence and Uncertain Legal Standards, Journal of Law, Economics, \& Organization, vol. 2, pp. 279-303.

Ellickson, R., 1991. Order without Law: How Neighbours Settle Disputes, Cambridge, MA, Harvard University Press.

Kaplow, L., 1990. Optimal Deterrence, Uninformed Individuals, and Acquiring Information about Whether Acts Are Subject to Sanctions, Journal of Law, Economics, \& Organization, vol. 6, 1, spring, pp. 93-128.

Kaplow, L. and Shavell, S., 1992. Private Versus Socially Optimal Provision of Ex Ante Legal Advice, Journal of Law, Economics, \& Organization, vol. 8, no. 2, pp. 306-320. 
Lando, H., 2007. Optimal Negligence Standards When One Party Is Ignorant of the Standards, Research in Law and Economics, no. 1, pp 207-216.

Miceli T., 2004. The Economic Approach to Law, Stanford University Press.

Posner, E., 2006. There Are No Penalty Default Rules in Contract Law, 33 Fla. St. U. L. Rev. 563.

Shavell, S., 1994. Acquisition and Disclosure of Information Prior to Sale, RAND Journal of Economics, vol. 25(1), spring, pp. 20-36.

Shavell, S. 1992. Liability and the Incentive to Obtain Information about Risk, The Journal of Legal Studies, vol. 21, no. 2, pp. 259-270.

Shavell, S., 1987. Economic Analysis of Accident Law, Cambridge, MA, Harvard University Press.

Verkerke, J.H., 2003. Legal Ignorance and Information-Forcing Rules. University of Virginia Law \& Economics Research Paper, no. 03-04, http://ssrn.com/abstract $=405560$.

Wittman, D., 1981. Optimal Pricing of Sequential Inputs: Last Clear Chance, Mitigation of Damages, and Related Doctrines in the Law, The Journal of Legal Studies, vol. 10, no. 1, pp. 65-91. 